\title{
Meta
}

Journal des traducteurs

Translators' Journal

\section{Corpus-based Critical Translation Studies: Research Areas and Approaches}

\section{Kaibao Hu et Xiaoqian Li}

Volume 63, numéro 3, décembre 2018

Traductologie de corpus : 20 ans après

URI : https://id.erudit.org/iderudit/1060164ar

DOI : https://doi.org/10.7202/1060164ar

Aller au sommaire du numéro

Éditeur(s)

Les Presses de l’Université de Montréal

ISSN

0026-0452 (imprimé)

1492-1421 (numérique)

Découvrir la revue

Citer cet article

Hu, K. \& Li, X. (2018). Corpus-based Critical Translation Studies: Research Areas and Approaches. Meta, 63(3), 583-603. https://doi.org/10.7202/1060164ar
Résumé de l'article

Cet article se concentre sur l'analyse de l'origine, des caractéristiques, des domaines de recherche, des méthodes de recherche et des implications des études de traduction critique basées sur le corpus, visant à établir son cadre théorique. On admet que les études de traduction critique basées sur le corpus, issues du mariage entre les études de traduction basées sur le corpus et les études de traduction critique, visent à dévoiler les facteurs idéologiques qui sous-tendent les traits des textes traduits et le processus de traduction. La naissance des études de traduction critique basées sur le corpus a non seulement révolutionné la méthodologie des études de traduction critique, mais a également élargi son champ d’application. 


\title{
Corpus-based Critical Translation Studies: Research Areas and Approaches
}

\author{
KAIBAO HU \\ Shanghai Jiao Tong University, Shanghai, China \\ kbhu@sjtu.edu.cn \\ XI AOQIA N LI \\ Shanghai Jiao Tong University, Shanghai, China \\ xqsjtu@163.com
}

\begin{abstract}
RÉSUMÉ
Cet article se concentre sur l'analyse de l'origine, des caractéristiques, des domaines de recherche, des méthodes de recherche et des implications des études de traduction critique basées sur le corpus, visant à établir son cadre théorique. On admet que les études de traduction critique basées sur le corpus, issues du mariage entre les études de traduction basées sur le corpus et les études de traduction critique, visent à dévoiler les facteurs idéologiques qui sous-tendent les traits des textes traduits et le processus de traduction. La naissance des études de traduction critique basées sur le corpus a non seulement révolutionné la méthodologie des études de traduction critique, mais a également élargi son champ d'application.
\end{abstract}

\begin{abstract}
This paper discusses the origin, features, research areas, and approaches, as well as the implications, of corpus-based critical translation studies (CCTS), with a view to establishing a theoretical framework. It is argued that CCTS, born of corpus-based translation studies and critical translation studies, will serve to unveil ideological factors behind the translated texts and the process involved. The birth of CCTS has not only revolutionized the methodology of critical translation studies, but has also broadened its scope.
\end{abstract}

\section{RESUMEN}

Este artículo aborda el origen, características, áreas de investigación, enfoques y repercusiones de los estudios críticos de traducción basados en corpus con el objetivo de establecer un marco teórico. El argumento que se presenta en este artículo es que los estudios críticos de traducción basados en corpus, derivados de los estudios de traducción basados en corpus y de los estudios críticos de traducción, servirán para identificar los factores ideológicos que influyen en los textos traducidos y en el proceso de producción. La llegada de los estudios críticos de traducción basados en corpus no solo ha revolucionado la metodología de los estudios críticos de traducción, sino que también ha ampliado su ámbito de investigación.

\section{MOTS CLÉS/ KEYWORDS/PALABRAS CLAVE}

études de traduction critique basées sur le corpus, domaines de recherche; méthode corpus-based critical translation studies; research areas; approaches estudios críticos de traducción basados en corpus; áreas de investigación; enfoques 


\section{Introduction}

Corpus-based critical translation studies (hereafter CCTS) refers to the branch of translation studies that investigates the relationship between translation and ideology within the framework of descriptive translation studies and with a corpus-based methodology, namely the statistical analysis of the features of translated texts. Translation studies imply the systematic study of translation, namely the theory, description, and applications of translation, interpreting, and localization. Descriptive translation studies (hereafter DTS) refer to the branch of translation studies that describes the features and roles of translation and of the translation process, with respect to the political, ideological, economic, and cultural contexts in which translated texts are produced. It aims to identify the principles that account for and predict what may occur in translation (Hu 2015: 4). Since the 1970s, the interplay between translation and ideology has attracted growing attention (Santaemilla 2005; Jiang, Guo, et al. 2006; Munday 2007; Jia 2008; Wang 2010; Yang 2010; Zhu 2011). As a result of the cultural turn in translation studies in the 1970s, theories from post-colonial studies, feminist studies and sociology have been applied to translation studies in an attempt to reveal the relationships between translation and various social institutions and/or systems, such as colonialism, gender, politics, and power, with ideology invariably being a key factor in these relationships (Fawcett 1995; Robinson 1997; von Flotow 1997; Gentzler and Tymoczko 2002; Aksoy 2010; Joz, Ketabi, et al. 2014; Wu and Zhang 2015). The ideological factors behind the features of translated texts and translation processes have, in recent years, been investigated by means of corpora and by drawing on the principles and methods of critical discourse analysis (Kenny 1998; Puurtinen 1998; Kemppananen 2000, 2004; Meng 2015; Zand 2015). These studies led to the birth and development of CCTS.

CCTS is of significance to both corpus-based translation studies (CbTS) and translation studies in general. The combination of CTS and CbTS broadens the scope of the former and allow the latter to shift its focus from the linguistic to the cultural. However, CCTS remains undefined in the eyes of most translation scholars. It is true that a number of studies have been conducted on ideology in translation, yet research in this field has been confined to the political sphere. The roles of gender, nationality, and individual ideology in translation have not been investigated with the use of corpora. Moreover, few studies have attempted to theorize CCTS as a sub-discipline of translation studies. This paper attempts to chart the territory of CCTS, with a focus on its research areas, approaches, and implications. The paper specifically addresses the following questions:

1) What is the relationship between CCTS and DTS?

2) What are the research areas of CCTS?

3) What are the possible approaches to conducting CCTS?

4) What are the theoretical and practical contributions that CCTS can make to CTS?

\section{The definition and features of critical translation studies}

As briefly mentioned in the introduction, CTS is the branch of translation studies that focuses on the relationship between translation and ideology within the broader framework of DTS. It analyzes the features of translated texts, as well as the use of translation strategies and methods, drawing on the analytical framework of critical 
linguistics and critical discourse analysis. As Laviosa (2004: 20) points out, CTS originates in the study of ideological elements in translation within the framework of DTS. CTS aims to investigate ideology in a broad sense, namely the "socially shared, general beliefs" (Van Dijk, 1998: 32) of a given society (norms, customs, values, etc.). In doing so, it differs from post-colonial, feminist or sociological approaches to translation, which investigate ideology in a narrower sense.

Generally, ideology is something internalized as common-sense by the people in a particular society, accepted and regarded as factual, beliefs that are taken for granted. According to Van Dijk (1998: 31), ideology has three components:

1) Cognition (thoughts and beliefs that generate ideas)

2) Society (group benefits, power, and control)

3) Discourse (the use of language, expressing certain types of social ideology, often related to concealment and control)

Translation, as Lefevere (1992/2004: 14) points out, "[...] is not made in a vacuum," but rather constitutes a kind of intercultural communication governed by all sorts of social factors and norms, including ideology. On the one hand, ideology has an influence on the production, distribution, and reception of translated texts. Such an influence is manifested at different levels, such as the choice of the source texts, the features of translated texts, and the translation strategies and methods adopted. On the other hand, translated texts can in turn strengthen or undermine individual or social ideology in the course of their distribution and reception. CTS aims to reveal the interplay between translation and ideology by analyzing the choice of the source texts, the reception of translated texts, the features of translated texts, and the translation strategies and methods that are used by translators.

CTS is in essence the integration of critical discourse analysis (CDA) and DTS. CDA was initiated by Fowler as a research approach to linguistics as early as 1979. Some publications, most notably Language and Power (Fairclough 1989) and Language, Power and Ideology (Wodak 1998) marked the eventual establishment of $\mathrm{CDA}$ as a discipline that investigates the meaning of discourse and the modes of its production, linguistic forms, and the meanings and mechanisms carried by these forms. Through the analysis of linguistic forms in texts, CDA tries to reveal the relationships between language, power, and ideology that underpin them and the ways in which the ruling class uses language to implement ideological control and to maintain its power and social status. CDA argues that discourse, as a social practice, is restrained by social structure, and at the same time influences and constructs social reality. On the one hand, discourse is the arena where social power is produced and reshaped, and where society and power are reproduced and challenged. On the other hand, the structure of discourse represents, strengthens, and reshapes power relations in society. In addition, discourse has a historical dimension, which requires re-contextualization. Discourse is produced or distributed in a particular historical or socio-cultural context. Thus, the interpretation of discourse requires placing it back in context.

The origins of DTS date back to 1953, when McFarlane published his paper entitled "Modes of Translation" (McFarlane 1953). He argued that the target text is not necessarily faithful to the source text, and that the nature of translation should be investigated based on the analysis of what actually takes place in translation. Later 
in 1972, Holmes first proposed the concept of DTS in his paper entitled "The name and nature of Translation Studies" (Holmes 1972/2000). Scholarly works such as those by Snell-Hornby (1988), Toury (1995), Hermans (1999), and Bassnett (1980/2004) followed, which fuelled the development of DTS. One of the basic tenets of DTS is that translation is a socio-cultural activity; it is governed by many socio-cultural factors and constraints, but also exerts influence on social ideology. Consequently, the translator's choices can be explained productively in terms of cultural and political constraints, for translation is performed in a historically specific, social and political context. Thus, translation may be examined by means of re-contextualization, which is placing the translation back in its original historical or socio-cultural context, in order to analyze the factors that governed its production.

It should be noted that CDA and DTS are similar in two ways. Both disciplines are concerned with the production and reception of texts in a given historical and socio-cultural context, arguing for a combined analysis of the features of a text and of its production and reception. Both investigate the relationships between the production and reception of texts and the social culture in which they exist. Furthermore, since translation is a special discourse or discourse practice, CDA principles and approaches are applicable to the analysis of the ideological factors at work in translated texts or in translation practice. These similarities make the marriage between CDA and DTS possible.

\section{The origin of CCTS}

CCTS have inherited insights from both CbTS and CTS. The former supplies research methodology, namely a descriptive-oriented and corpus-based approach, while the latter provides the analytical framework and guidelines. CbTS constitute "the branch of translation studies that investigates the nature of translation as a product and a process by means of corpora, based on the statistical analysis of the features of translated texts in relation to non-translated texts and the source texts" (Baker 1993). In fact, CbTS and CTS share significant common ground. Firstly, both of them originate from DTS and thus emphasize the role of translated texts in the cultural system of the target language. In other words, both focus on the interplay between translation and social or group ideology.

Secondly, both of them emphasize the combination of textual analysis and the analysis of the larger historical and cultural context. CbTS theorize on features of translation, translational norms, translator style, and so forth, on the basis of the analysis of the features of translated texts, in relation to a specific historical situation. Conversely, CTS investigate the ideological factors inherent to translation by analyzing the features of translated texts with respect to lexicons and syntactic structures. Thirdly, both rely on a relevant analytical framework to interpret their data, namely to identify possible reasons for the presence of particular features of translated texts or for the use of certain translation strategies. Fourthly, both adopt a comparative perspective: they compare source and target texts, or compare different translations of the same source text, in order to achieve a reasonable understanding of the features of translated texts and of the translation strategies and methods used within.

It is therefore reasonable to combine CbTS and CTS. Their existing affinities make the marriage between these two branches of translation studies highly produc- 
tive, opening the way for CCTS. As a matter of fact, the marriage between these two branches not only enriches CbTS, but also highly favours the development of CTS. Drawing on the advantages of corpus methodology, CCTS probes the ideological factors at work in translation by analyzing large amounts of bilingual or translational data, allowing CTS to generate evidence-based conclusions that are more generalizable and rigourous. In Hunston (2002: 109-128), seven corpus-based studies of ideology in language are reviewed. These studies, using corpus methodology, attempt to uncover implicit assumptions or hidden messages in texts through the analysis of keywords, semantic prosody, and repetitions. The term keyword, or focal word, is an important one in sociology (Firth 1969: 10). According to Firth (1969: 10), we can single out, from the whole lexical system of a culture, the lexical items that represent its mainstream values. These lexical items are referred to as keywords. For Scott and Tribble (2006: 55), keywords are those words whose frequency is well beyond normality. Semantic prosody is the tendency for a word or expression to be consistently used with either a positive or negative connotation. Clearly, ideology in translation can also be investigated by analyzing keywords and semantic prosody within corpora of translated texts.

\section{The major research areas of CCTS}

The major research areas of CCTS include, but are not limited to, the following: 1) corpus-based research on gender in translation; 2) corpus-based research on nationality in translation; 3) corpus-based research on politics in translation; 4) corpusbased research on a translator's individual or personal ideology.

\subsection{Corpus-based research on gender in translation}

This type of study has two main applications. On the one hand, it may describe the differences between male and female translators, in terms of the features of the texts they translate and of the translation strategies and methods they use, with the view to investigating the influence of gender on translation. On the other hand, focus can be placed on the role of translated texts in representing and constructing gender identity. Studies on gender and translation started in the 1970s, at the height of second-wave feminism and when the cultural turn began to take shape within translation studies. Against this backdrop, the relationship between gender and translation attracted the attention of translation scholars, and feminist translation theory gradually came into being. Feminist translation theory attempts to reveal the process by which translation is feminized and marginalized in traditional translation studies. According to this theory, translation is neither an imitation nor a derivative of the source text. Rather, it generates new meanings through cultural interference and mediation. Feminist translation theory is concerned with discrimination against women and with the poor regards for translators in traditional translation studies, both of whom are placed in a subordinate position. It also encourages fighting against and eliminating gender discrimination in the source texts through rewriting, so as to make female identity visible in the target texts. Feminist translation theory stresses and even exaggerates the role of translated texts in the construction of gender identity (Chamberlain 1988; von Flotow 1997). That being said, it pays no heed to the 
differences between male and female translators in terms of language use or translation methods employed.

Unlike feminist translation theory, corpus-based research on gender in translation neither advocates rewriting nor has any explicit political agenda. Studies of this kind rather focus on the differences between male and female translators in their use of particular lexicons or syntactic structures and in the translation strategies and methods they employ. Previous studies have found differences between males and females in terms of general language use, such as the following: 1) men prefer to use language for information transfer while women tend to use language for social purposes (Herring 1993; Brownlow and Parker 2003; Colley, Todd, et al. 2004); 2) women are more wordy than men in both writing and speaking (Mulac, Wiemann, et al. 1988; Mulac and Lundell, 1994); 3) men tend to use more negations and interrogations, while women favour imperative structures (Mulac, Seibold, et al. 2000); and 4) women more often use words or expressions that denote uncertainty, such as "I wonder if...." With regard to translation, the strategies and methods adopted by female translators have been found to be different from those of male translators when translating sex-related or gender sensitive lexical items (Meng 2015). CCTS that take gender into consideration can try to examine whether target texts produced by male and female translators display the same sex-dependent linguistic features that have been attributed to males and females through the study of general language, or if other differences are identified.

Let us now say a few words regarding the advantages and necessity of using corpora to do research on gender in translation. Hunston (2002: 119) argues that ideology, embodied in discourse, can be revealed through the analysis of language forms. Given this, incorporating corpora into the research on gender in translation allows scholars to investigate the interplay between gender and concrete linguistic forms, as revealed by the analysis of large numbers of translated or bilingual texts. This can effectively complement traditional feminist translation studies, where a qualitative or interpretative approach is usually adopted, based on the analysis of a limited number of linguistic features and texts, by giving a quantitative, more generalized, picture of gender in translation

Generally speaking, corpus-based research on gender in translation starts with an analysis of the differences between translated or interpreted texts, at the lexical, syntactical or discourse levels, by means of parallel corpora. These corpora comprise all translations of the same source text produced by male and female translators, in order to investigate whether and how the translator or interpreter's gender or gender awareness results in differential linguistic features in the translated texts. In addition, research in this field can also investigate the use by male and female translators or interpreters of target-language lexicons, target-language syntactic structures, translation strategies, and translation methods in order to find out what image of gender the translated texts or speech serve to construct.

\subsection{Corpus-based research on nationality in translation}

Nationality refers to a stable community that shares the same language, geographical area, economic life, and psychology, embodied in a common culture. Different ethnic groups, particularly those in different countries, have different social norms, cultural 
traditions, religious beliefs, and so forth, which influence translators as they produce a target text. Studies concerned with nationality wish to reveal the influence of national ideology on translation and the role translation plays in shaping national identity, by analyzing the features of translated texts as well as the strategies and methods employed by translators. Generally speaking, translators tend to, consciously or unconsciously, adopt methods such as free translation or deletion to eliminate cultural elements in the source texts that might be in conflict with their own national traditions or beliefs (Newmark 1988/2001: 49). To take sexual taboos as an example, translators from a society that is less tolerant of pornography tend to adopt a purification strategy, that is, rendering source-language sexual expressions with euphemistic or less sensitive lexical items. In addition, when translating words related to their own cultural traditions and beliefs, translators tend to adopt a foreignization strategy to make their own national culture and identity more visible. In fact, as a type of intercultural communication, translation can serve to promote the cultural identity of a nation, particularly that of ethnic minorities, and shape or reshape the image of a nation. At the end of the $18^{\text {th }}$ century, British orientalists, through translation, shaped an image of India as a lazy and submissive nation. However, since India gained independence from Britain, Indian scholars have strived to reshape the nation's image by translating Indian classics (Niranjana 1992: 53).

It is important to note, however, that a translator's strategies, methods, as well as lexical and syntactic choices can greatly influence the national or cultural image conveyed by his or her translation. In other words, studying the features of translated texts is an essential element in any study of the relationship between nationality and translation. However, before the rise of DTS, the linguistic features of translated texts had never been used to investigate the interplay between nationality and translation. For one thing, translated texts had long been regarded as unnatural and distorted texts, and thus were never studied as they deserve to be. For another, scholars at the time did not have access to techniques allowing large amounts of data to be analysed. Nowadays, corpus methods enable researchers to analyze the features of numerous translated texts, and thus to investigate whether and how national ideology impacts a translator's choice of lexicons and structures in the target language, as well as his or her use of particular translation strategies and methods. It also allows researchers to examine what national image a translator conveys in the target text, and how that image aligns with the expectations of the cultural community that he or she belongs to.

To give a more specific example, lexicon, syntactic structures, as well as translation strategies and methods can be analysed in a corpus of translated texts produced by translators with varied national allegiances or ethnic backgrounds. Analysis of these differences can help reveal the influence of the translator's national ideology on his or her translation. Moreover, all sentences containing keywords or expressions relating to nationality or ethnicity can be retrieved from a source text using a corpus methodology. By analyzing the target text equivalents of these words and expressions, we can see whether a shift has occurred in the process of linguistic transfer that has affected the national or ethnic image conveyed by the translation as compared to the original. For instance, a corpus-based method was adopted to study the image of the Hui nationality, an ethnic group in China, conveyed in The Last Quarter on the $M_{o o n}{ }^{1}$, the English translation of the Chinese novel 额尔古纳河右岸 ${ }^{2}$ by Chi Zijian 
(Wang 2015). Sentences containing words referring to Hui nationality and to two Hui characters were analyzed in the source and target texts. The study reveals that source-language words or expressions conveying a negative image of Hui nationality were left untranslated, while those with positive connotations were emphasized. This shows that translator Bruce Humes' ethnic ideology affected his translation of the novel.

\subsection{Corpus-based research on politics in translation}

A corpus-based approach to the study of translation products and processes can also be conducted with the aim of investigating the interplay between politics and translation. In particular, this kind of study can attempt to reveal the influence that the mainstream values of a society or the political beliefs shared by a party, a class or a country can have on translation. Conversely, it can investigate the role of translation in constructing or (re)shaping the image of a class, party or country, or its role in shaping the mainstream values of a society. It is generally acknowledged that translation is, in essence, a social activity, for translators are inevitably influenced by the values, beliefs or ideas of the social class, political party or country to which they belong. Moreover, translation is often employed as an important tool to promote a particular value or political idea. For instance, Jia (2008) studied how the American magazine Newsweek translates words related to Chinese culture and policy. The results show that the translators, under the influence of the values and political beliefs of the country they live in, tend to distort China's image and misrepresent China's policy by using linguistic markers of ideology, such communist. Laviosa (2000), using the Translational English Corpus, investigated five semantically related words European, Europe, European Union, Union, and EU - and their collocates in the translated news articles of The Guardian and other European newspapers. Her results show that the translated texts construct a non-aggressive and non-conflictual image of Europe, one that is presented in a detached and objective manner.

In addition, corpus-based research on politics in translation can also focus on how translators represent the political beliefs or values of a given organization or country in their target text. Using a small corpus, Gumul (2011) conducted a contrastive analysis between English news articles on the 2003 Iraq war and their translations published in the Polish magazine Forum. The analysis reveals a shift in the translated texts with respect to the use of linguistic markers of ideology, namely those relating to nominalization, transitivity, modality, and cohesion. For his part, Munday (2007) studied a proclamation signed by former Cuban leader Fidel Castro and its English translation published in an official Cuban newspaper. The original Spanish proclamation informed the public that Fidel Castro was temporarily handing over power to his brother Raul Castro due to health reasons. In it, all the actions are described by means of past participles and infinitive phrases, without mentioning Fidel Castro. In the English translation, however, Fidel Castro is an active figure and his illness is portrayed as resulting from external pressures rather than from a chronic condition; this is done through frequent collocations of first-person pronouns and nominalizations or verbs, such as my visit, my participation, and I attended. Clearly, the translated text attempts to convey the message that Fidel Castro was only handing over power temporarily, thereby dispelling possible worries about his health. 
Corpus-based research on politics in translation can be performed by analyzing translated texts, which involves three steps. Firstly, one should describe the linguistic features of translated texts, as well as the translation strategies and methods used therein, by means of corpora, and then identify general patterns in the use of particular lexical items, syntactic structures, translation strategies, and translation methods, with the help of statistical analyses. Particular emphasis should be placed on the use of evaluative lexical items or linguistic markers of ideology in the translated texts. Secondly, one should describe common patterns in the use of translation strategies and methods, based on the analysis of correspondences between source- and target-language lexicons or structures, particularly those relating to political beliefs or to the political systems of a given political party or organization. To examine the influence of political beliefs on translation, two or more translations of the same source text, produced by translators from different countries or with different political affiliations, can be analyzed with the aim of showing possible differences in the use of certain translation strategies and methods. Thirdly, one should interpret the interactive relationship between political beliefs and translation in light of the general patterns identified through the above-mentioned corpus-based and critical analyses.

\subsection{Corpus-based research on individual ideology in translation}

Ideology is generally divided into group ideology and individual, or personal, ideology. The former refers to the views or thoughts on nature or society shared by a social group or a political party, or the beliefs, values, and opinions of a nation or country, while the latter is an individual's socio-cultural beliefs and values, which have taken shape during a certain period of time or in a certain historical context. An individual is influenced by group ideology, yet he or she also forms his or her own individual ideology, distinct from that of other members of the society. A translator's individual ideology, which may be different from that of others, includes his or her values, translation thoughts, and translation goals. It is widely accepted that the translator's individual ideology influences not only his or her choice of the source text, but also his or her choice of target-language lexicons and syntactic structures, as well as the choice of translation strategies and methods, except perhaps if he or she works for a translation agency or a government. However, although a translator working for a company or government does not choose the texts to be translated, his or her values and beliefs can still impact his or her translation.

Scholars engaged in corpus-based research on a translator's individual ideology analyze the linguistic features of the target text, as well as the translation strategies and methods used, as a way to investigate his or her values and goals. Generally, studies of this kind focus on the translation of typical lexical items or structures in the source text and on regular patterns in the use of lexical items or structures in the target text. Comparison can unveil differences between the styles of different translators, which can then be studied to uncover the ideological factors that contribute to these differences.

For instance, Baker (2000) conducted a corpus-based analysis of the translations of two British translators, Peter Bush and Peter Clark. She found that the latter's translation is more explicit than the former's. She argues that this difference is attributable to the translators' individual ideology, which includes their goals and attitudes 
towards the readers of the target texts. Similarly, Hou (2010) investigated the differences between three Chinese translations of Shakespeare's plays by Liang Shiqiu, Zhu Shenghao, and Fang Ping respectively, focusing on the translations of sex-related words or expressions. The results show that Zhu most frequently adopted a purification strategy and avoided mentioning sexual organs or sex acts as much as possible. Liang often translated them literally, but Fang tended to adopt a literal translation even more frequently than Liang and Zhu. Hou pointed out that these differences are likely caused by the translators' different goals. Liang intended his translations of Shakespeare's plays to "'arouse the readers' interest in the source texts" (1981: 18), and thus, he was loyal to the original as much as he could. However, Zhu Shenghao wanted to make Shakespeare known to the general Chinese readership. As a result of a traditional upbringing, he was most conservative in matters of sex (Zhu 1991: 263). Fang (2005), on the contrary, argued that vulgar expressions in Shakespeare's plays should be rendered into vulgar expressions in the target language, without polishing, as the use of these expressions is one of the important features of Shakespeare's plays. Finally, using a Chinese-English parallel corpus of Hongloumeng, Li, Zhang, et al. (2011) analyzed the stylistic differences between two English versions of Hongloumeng, a classic Chinese novel. The authors argue that the differences observed between the two translations are due to various factors, namely the two translators' differing primary goals, their consciousness of a clear target readership, and their concern for the readers, in addition to the social, political, and ideological milieu in which they both lived and worked.

It should be noted that, for corpus-based research on a translator's individual ideology, a study should be designed in such a way as to isolate a translator's individual ideology as a variable serving to distinguish between different translated texts. Other variables, including social ideology, should be accounted for and their impact minimized as much as possible. For this type of research, the preferred object of study is a corpus composed of several different translations of the same source text by translators with a shared social ideology. A comparative analysis can then be performed to identify differences in the use of target-language lexicons and structures, as well as in the use of translation strategies and methods. Finally, possible explanations for the observed differences between the different translations can be examined in line with DTS theories. Generally, a host of factors can be responsible for these, such as textual, individual, and socio-cultural factors. Textual factors include the source text and the textual conventions of the target language. Individual factors refer to the translator's individual ideology, including his or her translation goals. Socio-cultural factors refer to social ideology. For translators with a shared social ideology and who are translating the same source text, the differences between their target texts may be reduced down to differences between their individual ideologies.

\section{Research approaches to CCTS}

As mentioned above, drawing on the theories and approaches of CbTS and critical discourse analysis, CCTS aims to reveal the hidden ideological factors behind translation products and processes by analyzing the features of translated texts as well as the strategies and methods employed by translators. CCTS can be approached from 
the following vantage points: 1) transitivity and ideology in translation; 2) nominalization and ideology in translation; 3) modality and ideology in translation; 4) classification and ideology in translation; and 5) keywords, sensitive words, and ideology in translation.

\subsection{Transitivity and ideology in translation}

Within systemic functional linguistics (Halliday and Matthiessen 1985/2004: 309), transitivity refers to the grammatical system that allows the speaker to structure experience; it derives from the ideational metafunction (more specifically, the experiential metafunction).

Our most powerful impression of experience is that it consists of a flow of events, or 'goings-on.' This flow of events is chunked into quanta of change by the grammar of the clause: each quantum of change is modelled as a figure [...]. All figures consist of a process unfolding through time and of participants being directly involved in this process in some way; and in addition there may be circumstances of time, space, cause, manner or one of a few other types. Thus [...] the clause is also a mode of reflection, of imposing order on the endless variation and flow of events. The grammatical system by which this is achieved is that of TRANSITIVITY. (Halliday and Matthiessen 1985/2004: 170)

The system thus encompasses the relationships between participants in a communicative situation, as well as the relationships between the participants' activities and states, and the circumstances. Transitivity structures the world of experience into six process types: material, mental, relational, behavioural, verbal, and existential. Material process clauses are "clauses of doing- $\&$-happening" (Halliday and Matthiessen 1985/2004: 179), while mental process clauses are clauses of sensing, concerned with "our experience of the world of our own consciousness" (Halliday and Matthiessen 1985/2004: 197). Relational process clauses relate one fragment of experience to another in circumstance; they serve to identify and classify. Behavioural process clauses describe the outer manifestations of the psychological or physiological states of participants, such as sighing, breathing, and dreaming. The verbal process refers to the "symbolic relationships constructed in human consciousness and enacted in the form of language, such as saying and meaning" (Halliday and Matthiessen 1985/2004: 171). Finally, existential process clauses are used to recognize that all kinds of phenomena exist or happen; they are concerned simply with existence.

The process type of transitivity chosen by the speaker reflects his or her communicative intentions and viewpoints; it can also embody the social or group ideology of the context in which the speaker lives. Additionally, the way in which the participants and circumstances of a specific process are arranged also reflects the speaker's communicative intentions and guides the reader to perceive a certain event from a particular perspective. The nature of the process - which implies particular relationships between participants, as well as between participants and circumstances - can thus suggest the ideological implications of a text. For example, the British newspapers The Guardian and The Times reported on a riot on June $2^{\text {nd }}, 1975$, and The Observer on that same riot on June $8^{\text {th }}, 1975$. The headlines and the first sentences of each report read as follows: 
1) Eleven killed by police in Salisbury riot.

Eleven Africans were killed and 15 wounded today when Rhodesian police fired on rioters in African townships on the outskirts of Salisbury. (The Guardian) ${ }^{3}$

2) Rioting blacks shot dead by police as ANC leaders meet.

Eleven Africans were shot dead and 15 wounded when Rhodesian police opened fire on a rioting crowd [...]. (The Times) ${ }^{4}$

3) Riot followed power bid by Joshua Nkomo.

A power bid by African nationalist leader Joshua Nkomo led directly to last Sunday's riots during which Rhodesian police shot dead 15 African. (The Observer) ${ }^{5}$

All three examples shown above are material process clauses. However, the active voice is used in Example 3 to profile the actor of the gun-shooting incident. Conversely, in Examples 1 and 2, the passive voice is used: the patient or the victim is placed in a prominent position, while the actor's place is diminished, so that accountability awareness is undermined.

Since all the different processes construed by transitivity are expressed through verbs, other parts of speech or structures, a list of these elements can be retrieved from a corpus of source and target texts. Based on parallel concordance lines featuring elements that express processes of transitivity, one can thoroughly analyze the translation shifts identified in the target text as well as uncover the ideological factors that may explain these shifts. A concordance line is a line of text from the corpus that may consist of one sentence, part of a sentence or even two sentences. According to Fairclough (1992: 180), the choice of one of the processes to describe/translate what is happening embodies cultural, political or ideological meaning. For example, one can extract all the passive constructions from a parallel corpus of news reports to examine their occurrences and patterns in the target and source texts. Contrastive analysis can reveal possible ideological factors behind the use of the passive voice and can suggest the role it plays in the construction of ideology in the target text(s).

\subsection{Nominalization and ideology in translation}

Nominalization can be interpreted in a broad or a narrow sense. Broadly speaking, nominalization involves verbs, adverbs, adjectives, and other parts of speech being used as a noun or the head of a noun phrase. In the narrow sense, it refers to the addition of a derivational affix to verbs and adjectives in order to produce nouns. In this paper, nominalization is employed in its narrow sense. Often considered a syntactical process or result, nominalization is one of the thirteen grammatical metaphors proposed by Halliday and Matthiessen (1999), namely, the grammatical metaphor of transference from adjective, verb, and preposition to noun. Fairclough (2008: 815) argues that nominalization is both a syntactical and a textual process, as well as a psychological and historical process.

It should be pointed out that the choice and application of nominalization also have ideological implications. Firstly, nominalization conceals the actor of a given event and thus diverts the readers' attention from him or her. As van Dijk (2008: 19) pointed out, the speaker/writer often uses nominalization to conceal or downplay the actor's bad intentions. Secondly, nominalization usually conceals the precise moment an event took place and thus blurs the time line. As a result, the event or act 
can be depicted as recurring or continuous. In the statement delivered by George W. Bush, former President of the United States, in the wake of the 9/11 attacks, the nominalization "terrorist attacks" was used to gain the support of the international community in the fight against terrorism. Finally, with nominalization, new information can be presented as known information or a shared presupposition, likely to be taken as fact by the reader. The information conveyed is thus naturalized and more often than not it exerts influence on people's judgments and thoughts. That being said, the ideological factors underpinning the translation process and the translation product can be revealed by investigating the nominalization choices adopted by the translators. On the one hand, nominalizations in the source text can be analyzed to reveal potential ideological hotspots that can influence the translation process and thus that may be more likely to present translational shifts in the target text. On the other hand, nominalizations in the target text can be compared to those in the source text.

Generally speaking, studies on nominalization and ideology in translation involve the following steps. First, one must retrieve all the instances of nominalization in a given parallel corpus (source and target texts), namely nouns that are derived from verbs or adjectives. This can be done through a query for nouns with the suffixes -tion, -sion, -ment, -ness, and -ity in the case of English, as they are typical of nominalization in English. In the case of Chinese, suffixes such as 度 and 性, which signal nominalization in Chinese, can be used as a search query to retrieve instances of nominalization. Furthermore, the WordList function of WordSmith, a software tool for corpus-based studies developed by Mike Scott, can be used to generate a word list from the source and target texts. This word list allows instances of nominalization with a zero suffix to be identified. Secondly, one must analyze the instances of nominalization. A statistical analysis of the retrieved instances of nominalization can be performed in order to uncover possible measurable trends in the use and translation of nominalizations. For instance, different translations of a given source text, produced by translators from different national or ethnic backgrounds, can be compared to identify differences in their use of nominalizations or in the way they translate them. Thirdly, one must investigate how ideological factors can explain or contextualize the nominalization results obtained in the previous steps.

\subsection{Modality and ideology in translation}

Modality is used to express the degree of the speaker's commitment to the truth of his or her proposition, or the speaker's promise or obligation to a future course of action. It can also reflect the social distance and power relations between the parties involved in the communicative event.

Modality mainly involves modal verbs, modal adjectives, modal adverbs, and pronouns. Modal verbs, also known as modal auxiliaries or modal operative words, are auxiliary verbs that express possibility or necessity. According to Palmer (1989: 35), modality can be classified into epistemic modality, deontic modality, and dynamic modality. First, epistemic modality expresses the speaker's judgment as to the degree of truth of a proposition. Second, deontic modality allows the speaker to express the subject's responsibilities and obligations. Third, dynamic modality is used by the speaker to describe the subject's capabilities and willingness. Modal adjectives 
and adverbs - such as probable, likely, necessary, definitely, perhaps, important, significant, imperative, unfortunately, happily - express the possibility or necessity of a specific event or the speaker's attitudes and judgments. Modal verbs, modal adjectives, and modal adverbs reflect the speaker's judgment toward a certain event or person, as well as the power relations between the parties involved in communication. For example, the use of must and should indicates that the speaker has more power than the audience in the communicative situation. Therefore, one can analyse how modals in the source text are translated or how they are used in the target text(s); this analysis can reveal any shifts in the values and attitudes expressed by the target text(s) as compared to the source text, and thus in the ideological meaning that both texts intend to convey.

Personal pronouns are classified into first-, second-, and third-person pronouns, each category having singular and plural forms. The social status of the participants in a communicative situation and the social distance between them usually constrains the choice of personal pronoun for each participant. Brown and Gilman (1972: 252) point out that personal pronouns are significantly involved in two social dimensions of discourse, namely, power operations and solidarity between the participants. Xin (2005: 75) argues that the selection of personal pronouns usually depends on social status, power relations, and the intimacy shared by the two parties. For example, the English first-person plural pronoun we and its Chinese counterpart 我们 both have inclusive and exclusive uses, but 咱们, a derivative form of the Chinese first-person plural pronoun, only has an inclusive use. According to Fowler, Hodge, et al. (1979: 203), the exclusive use of the first-person plural pronoun tends to enhance the social distance between speaker and audience, while the inclusive use usually diminishes it. Given the ideological connotations that personal pronouns can convey, the first-person plural pronoun in particular, CCTS can approach them from the following perspectives: 1) one can study the personal pronouns featured in the source text and the ideological meaning they convey; 2) one can identify patterns in the translation of personal pronouns in the target text(s) and the possible ideological meanings the translator(s) thus invest(s) in the translation(s); and 3) one can study the interplay between ideology and the use of personal pronouns in the target text(s). Zhu (2011) and Lakoff (1990) give good examples. Using a Chinese-English parallel corpus of Chinese Government Work Reports published between 2000 and 2009, Zhu (2011) investigated the use of the first-person plural pronoun in the English target texts. It was found that most of the first-person plural pronouns are not present in the Chinese source texts, but were rather added by the translators. Zhu argues that the frequent adoption of the first-person plural pronoun in the target texts is attributable to the translators' attempts to shorten the social distance between the government and the readers, by virtue of the inclusive meaning of that personal pronoun. It is known that, in addition to its inclusive and exclusive meaning, the first-person plural pronoun "we" is often used to refer to royal families and other people with high social status (Lakoff 1990: 190). Given this, "we" is also often used, Zhu argues, to project the authoritativeness of the Chinese Government. 


\subsection{Classification and ideology in translation}

Classification refers to the designation and description of human beings, objects, and events through lexical means in texts. According to Fowler, Hodge, et al. (1979: 210), classification grants order to the external world by means of language, yet it is not necessarily contingent on the inherent nature of the world but is rather influenced by the designator's positions and beliefs. Moreover, the designation and description of a specific entity may change over time. In addition, choice of designation can embody people's attitudes towards the designated entity (Simpson 1993: 141). Linguistic classification can therefore be ideologically motivated and thus it may produce bias and discrimination. Munday (2007) reveals that, in reports published in the American magazine Geopolitical Review on January $17^{\text {th }}$, March $14^{\text {th }}$, May $31^{\text {st }}$, and June $24^{\text {th }}$ of 2005, the former president of Venezuela, Hugo Chavez, was respectively referred to as: 1) Venezuelan "President" Hugo Chavez; 2) Venezuela's leftist leader Hugo Chavez; 3) Venezuela's socialist/communist leader Hugo Chavez; and 4) Venezuela's despot Hugo Chavez. In the first instance, the fact that the title 'president' was bracketed by quotation marks indicates disrespect to Chavez and challenges the legitimacy of his presidency. The second title is neutral. However, the inclusion of "socialist" and "communist" in the third form, two words that carry negative political connotations in the United States, suggests clear distaste for Chavez. The fourth title is again a blatant attack. In addition to the ideological implications of designation, the description of a person or event may also reflect different positions or viewpoints. For example, when reporting the UK military deployment in Basra during the Iraq war, the UK newspaper The Telegraph ${ }^{6}$ used positive lexical items such as "pave the way" and "Britain's responsibility for administering," whereas The Independent $t^{7}$ adopted lexical items with negative connotations, such as "ill-starred attempt," "unclear," "unpopularity," and "with very little achieved." The contrast between these lexical choices represent the opposing views of the two newspapers.

Comparatively speaking, classification in the target text is much more complicated than in the source text, because translations must contend not only with the ideology conveyed by the source texts but also with the ideology of the society in which the translators live as well as with their own individual ideology. On the one hand, some lexical instances of classification in the target text may reproduce the positions and viewpoints expressed in the source text, while others might express an ideological shift or deviation from the source. These shifts or deviations in turn reflect the translator's subjectivity and ideology. On the other hand, some lexical instances of classification in the target text may not be motivated by the source text and may have been added by the translator. This reflects the translator's attitudes towards the ideology conveyed by the source text and expresses the translator's judgment of an entity.

Within CCTS, it is possible to compare the classification system between the source and target texts in order to study the interaction between ideology and translation. Specifically, one can search for nouns and pronouns that designate people or entities in a source corpus and retrieve the parallel concordance lines containing these words. By analyzing the contexts of these lexical items, especially the co-occurring adjectives, verbs, and nouns that describe or modify them, the differences between the source and target classification systems can be identified and any ideological shifts that might have occurred in translation can be revealed. Moreover, by means of the 
WordList function of linguistic analysis software programs, such as ParaConc, AntConc or WordSmith, high-frequency content words in the source and target texts, particularly content words with value indication, such as "devout," "violence," and "courage," can be compared. The analysis of the differences between source and target texts in describing the same person or issue can also reveal shifts that might have occurred in translation and the ideological factors underpinning them.

\subsection{Keywords, sensitive words, and ideology in translation}

Stubbs (1996: 168) argued that analyzing keywords or lexical items that occur repeatedly is important for the study of the link between language and ideology, as these are generally cultural representations. Keywords often convey social ideology and, in a given text, the words with high keyness, or the quality of being "key" in a linguistic context, are often used by the speaker/writer to express his or her ideology through discourse. Normally, ideology in a specific text is linguistically realized through lexis, lexico-grammar, narration, and so forth. Keywords can thus be one of the most effective ways to approach the ideological elements that are woven into the linguistic matrix of the text. It is therefore reasonable to consider the study of keywords and of their collocates, including semantic prosody, as important approaches in CCTS.

The KeyWords function in WordSmith and in other software tools can be used to generate keyword lists from the source texts, target texts, and non-translated texts in a large corpus, then keyword lists that can be compared. The role of ideology, including individual ideology, in constructing discourse can be examined through an analysis of the collocations and of the semantic prosody of the keywords shared by the non-translated texts, the source texts, and the translated texts. For example, Olohan (2004: 160) compared Lawrence Venuti's translation of an Italian work of fiction $(214,919$ words in total) with the BNCFIC (4,947,688 words in total), the fiction sub-corpus of the British National Corpus, using the KeyWords function in WordSmith. The analysis reveals that Venuti prefers to use archaism in his translation, deliberately using them to indicate, "the temporal remoteness of the Italian texts, their emergence in a different cultural situation at a different historical moment" (Venuti, 1998: 14).

Additionally, sentences that contain keywords in the source text and the correspondent sentences in the target text(s) can be extracted to compare these keywords and their target-language equivalents in terms of semantic prosody. Shifts in semantic prosody in the translation(s) may reveal the social ideology that influences the translator(s) and his or her individual ideology. Kemppanen (2004), for instance, studied the Finnish keyword ystävyys (friendship) in a corpus of non-translated Finnish texts and Finnish translations of Russian source texts. The results show that this word more often collocates with positive lexical items in the translated texts, thus producing a positive semantic prosody, whereas it co-occurs with negative words more frequently in the non-translated texts, thus generating a negative semantic prosody. Kemppanen argues that the translated Finnish texts attempt to promote friendship as a value.

Sensitive words refer to lexical items with obvious political, violent or vulgar connotations. These words usually run counter to the mainstream ideology or socio- 
cultural norms of a society or country. They may elicit a strong emotional response from the translator(s) and the target readers or insult the deities or cultural traditions of the target culture. Generally speaking, the methods used to translate sensitive words are literal translation, free translation, and omission (Newmark 1988/2001: 50). Literal translation implies that the translator chooses to identify himself or herself with the ideological stance or meaning these words convey. Conversely, free translation or omission indicates that the translator does not accept it, or that he or she believes they may be blasphemous in the eyes of the target readers. Therefore, analyzing the strategies used to translate sensitive words is an effective way to examine the influence of social and individual ideology on translation.

\section{Implications of CCTS}

CCTS was born out of the widespread use of corpora in CTS. The application of corpora in CTS is significant in that it not only brings about a major change in its research methodology but also broadens its scope.

\subsection{A major change in the research methodology of CTS}

In CTS, qualitative analysis used to prevail, as researchers tended to investigate the relationship between ideology and translation by virtue of introspection or analysis of a small number of texts. However, CCTS introduces a corpus-based approach and quantitative analysis into the landscape. This can be regarded as a revolutionary methodological change for the following reasons. Firstly, the use of corpora allows large amounts of data to be analyzed, which enables researchers to capture regular patterns in the use and translation of typical words and structures and to examine the possible ideological motivations behind these patterns. Secondly, statistical analyses performed by corpus software programs, such as word frequency and the frequency of typical structures, can be applied to textual analysis with a focus on ideology, a rather elusive notion that can hardly take any concrete form otherwise. Thirdly, corpus data may not only confirm or disprove one's intuitions and hypotheses about language use, they can also reveal some linguistic facts that are otherwise invisible to the naked eye or overlooked in qualitative studies. In sum, the introduction of corpora into CTS can effectively compensate for the researcher' subjectivity and render the conclusions more reliable and generalizable.

\subsection{A wider research scope for CTS}

Before corpus-based methodology was used, CTS were confined to the analysis of a few typical lexical items and structures, such as designation, evaluative modifiers, and passive constructions in the translated texts. However, corpus-based methodology has widened the scope of CTS, allowing for the analysis of other linguistic phenomena, such as word frequency, keywords, clusters, collocations, semantic prosody, and so forth, all of which may reflect ideology. On the one hand, the use of corpora allows scholars to generalize the tendencies in the above linguistic features and to analyze the ideological factors underpinning them. On the other hand, the use of corpora can help identify linguistic units with ideological meaning, which can hardly 
be done manually. In addition, by using corpora, researchers are able to identify naturally occurring linguistic patterns and provide examples that are either frequently or rarely used, or examples that would be overlooked in small-scale data analysis (Baker and McEnery 2005: 197).

\section{Conclusion}

Substantial progress has been made in research on the interplay between ideology and translation since the 1970s, as a result of the cultural turn in translation studies. Although a great number of studies have been conducted in this field, research topics have most often been confined to the relationship between translation and politics, or to ideology in the narrow sense. Gender, nationality, and individual ideology have not been deeply investigated in translation studies with the use of corpora. Few studies have ever attempted to theorize CCTS as a branch of translation studies. Against this backdrop, the present paper proposes to consider CCTS as a branch of translation studies and attempts to establish its theoretical framework. It is argued that CCTS is essentially the combination of CbTS and CTS. Its research areas include corpusbased research on gender, nationality, and politics in translation, as well as individual ideology in translation. CCTS can namely be approached from the perspectives of transitivity, nominalization, modality, classification, keywords, and sensitive words.

As a new branch of translation studies, CCTS is still in its infancy and must still confront numerous obstacles, although advances have been made in corpus-based research on politics in translation. However, CCTS not only brings about profound changes in the research methodology of CTS, it also expands its scope from politics to gender, nationality, and individual ideology in translation. Given the importance of research on ideology in translation and the advantages of corpus methodology, efforts should be made to promote CCTS. This can be achieved by developing specialized corpora for research on ideology in translation, as well as combining quantitative and qualitative methodologies. Moreover, priority should be given to corpus-based studies of gender, nationality, and individual ideology in translation, which have hitherto been ignored by translation scholars.

\section{NOTES}

1. Chi, Zijian (2010/2013): The Last Quarter of the Moon. (Translated by Bruce Humes) London: Harvill Secker.

2. CHI, Zijian (2010): 额尔古纳河右岸 (Éěrgǔnàhé yòuàn) [The Right Bank of the Ergun River]. Beijing: People's Literature Publishing House.

3. Miller, Henry (2 June 1975): Eleven killed by police in Salisbury riot. The Guardian. 1.

4. Cleary, Frederik (2 June 1975): Rioting blacks shot dead by police as ANC leaders meet. The Times. 59411:1.

5. Martin, David (8 June 1975): Riot followed power bid by Joshua Nkomo. The Observer. 6.

6. Coughlin, Con (16 December 2007): Britain hands Basra back to the Iraqis. The Telegraph. Visited 15 September 2018, <https://www.telegraph.co.uk/news/worldnews/1572736/Britain-hands-Basraback-to-the-Iraqis.html>.

7. CосквuRn, Patrick (17 December 2007): Britain bows out of a five-year war it could never have won. The Independent. Visited on 14 September 2018, <https://www.independent.co.uk/news/ world/middle-east/britain-bows-out-of-a-five-year-war-it-could-never-have-won-765466.html>. 


\section{REFERENCES}

Aкsoy, Berrin (2010): The Relation between Translation and Ideology as an Instrument for the Establishment of a National Literature. Meta. 55(3):438-455.

BAKER, Mona (1993): Corpora linguistics and translation studies: Implications and applications. In: Mona BAKer, Gill Francis, and Elena Tognini-Bonelli, eds. Text and Technology: In Honour of John Sinclair. Amsterdam/Philadelphia: John Benjamins, 233-250.

BAKER, Mona (2000): Towards a Methodology for Investigating the Style of a Literary Translator. Target. 12(2):241-266.

BAKer, Paul and McEnery, Tony (2005): A Corpus-based Approach to Discourses of Refugees and Asylum Seekers in UN and Newspaper Texts. Language and Politics. 4(2):197-226.

BAssnett, Susan (1980/2004): Translation Studies. $3^{\text {rd }}$ ed. Shanghai: Shanghai Foreign Language Education Press.

Brown, Roger and Gilman, Albert (1972): The Pronouns of power and solidarity. In: Pier Giglioli, ed. Language and Social Context. Harmondsworth: Penguin, 252-282.

Brownlow, Rosamon and Parker, Rosamon (2003): Gender-linked Linguistic Behavior in Television Interviews. Sex Roles. 49:121-132.

Chamberlain, Lori. (1988). Gender and the Metaphorics of Translation. Signs.13(3):454-472.

Colley, Ann, Todd, Zazie, Bland, Matthew, et al. (2004): Style and Content in Emails and Letters to Male and Female Friends. Journal of Language and Social Psychology. 23(3):369378.

FawCETt, Peter (1995): Translation and Power Play. The Translator. 1(2):177-192.

Fairclough, Norman (1992): Discourse and Social Change. Cambridge: Cambridge Polity Press. FAirclough, Norman (1989): Language and Power. London: Longman.

FairClough, Norman (2008): The Language of Critical Discourse Analysis: Reply to Michael Billig. Discourse \& Society. 19(6):811-819.

FANG, Ping (2005): 翻译艺术和戏剧艺术结缘 [The Convergence of the Art of Translation with the Art of Drama]. Journal of Sichuan International Studies University. 28(1):1-3.

FirTh, John (1969): The Technique of Semantics. Papers in Linguistic Theory 1934-1951. Oxford: Oxford University Press.

Fowler, Roger, Hodge, Bob, Kress, Gunther, et al. (1979): Language and Control. London: Routledge \& Kegan Paul.

Gentzler, Edwin and Tyмосzко, Maria (2002): Translation and Power. Amherst: University of Massachusetts Press.

Gumul, Ewa (2011): Translational Shifts of Syntactic and Lexical Markers of Ideology: Reporting the Iraqi Conflict in Polish Reprint Press. Meta. 56(4):758-774.

Halliday, Michael and Matthiessen, Christian (1999): Construing Experience through Meaning. London: Continuum.

Halliday, Michael and Matthiessen, Christian (1985/2004): An Introduction to Functional Grammar. $3^{\text {rd }}$ ed. London: Hodder Arnold.

Hermans, Theo (1999): Translation in System: Descriptive and System-oriented Approaches Explained. Manchester: St. Jerome.

Herring, Susan (1993): Gender and Democracy in Computer-mediated Communication. Electronic Journal of Communication. 3(2):476-489.

Holmes, James (1972/2000): The Name and Nature of Translation Studies. In: Lawrence VenUti, ed. The Translation Studies Reader. London/New York: Routledge, 172-185.

Hou, Yulu (2010): A Corpus-based Study of the Chinese Translations of Sensitive Words in the Plays by Shakespeare. Master's thesis, unpublished. Shanghai: Shanghai Jiao Tong University.

Hu, Kaibao (2015): Introducing Corpus-based Translation Studies. Berlin: Springer.

Hunston, Susan (2002): Corpora in Applied Linguistics. Cambridge: Cambridge University Press.

JiA, Hui (2008): 意识形态与美国《新闻周刊》涉华词语的翻译 [Ideology and the English Translation of the Words Related to China in Newsweek]. Shanghai Journal of Translation. 23(2):27-31. 
JIANG, Qiuxia, Guo, Laifu, JING, Ping, et al. (2006): 社会意识形态与外国文学译介转换策 略——以狄更斯的《大卫.考坡菲》的三个译本为例 [The Influence of Social Ideology on Translation of Foreign Literature: A Case Study of Three Chinese Versions of David Copperfield]. Foreign Literature Studies. 28(4):166-175.

Joz, Rasool, Ketabi, Saeed, Dastjerdi, Hossein, et al. (2014): Ideological Manipulation in Subtitling: A Case Study of a Speech Fragment by Mahmoud Ahmadinejad (President of the Islamic Republic of Iran). Perspectives. 22(3):404-418.

Kemppanen, Hannu (2004): Keywords and Ideology in Translated History Texts: A Corpusbased Analysis. Across Languages and Cultures. 5(1):89-106.

Kenny, Dorothy (1998): Creatures of Habit? What Translators Usually Do with Words. Meta. 38(4):515-523.

Lakoff, Robin (1990): Talking Power: The Politics of Language. New York: Basic Books.

LAVIosA, Sara (2000): TEC: A Resource for Studying What is "in" and "of" Translational English. Across Languages and Cultures. 1(2):159-178.

Laviosa, Sara (2004): Corpus-based Translation Studies: Where Does It Come from? Where Is It Going? Language Matters. 35(1):6-27.

Lefevere, André (1992/2004): Translation/History/Culture: A Sourcebook. Shanghai: Shanghai Foreign Language Education Press.

LI, Defeng, Zhang, Chunling, and Liu, Kanglong (2011): Translation Style and Ideology: A Corpus-assisted Analysis of Two English Translations of Hongloumeng. Literary and Linguistic Computing. 26(2):153-166.

LIANG, Shiqiu (1981): 关于莎士比亚戏剧翻译 [On the translation of the plays by Shakespeare]. In: Jingzhi LiU, ed. 翻译论集 [On Translation]. Hong Kong: Sanlian Press, 16-18.

McEnery, Tony and Hardie, Andrew (2012): Corpus Linguistics: Method, Theory and Practice. Cambridge: Cambridge University Press.

McFarlane, John (1953): Modes of Translation. The Durham University Journal. 45(3):77-93.

MeNG, Lingzi (2015): 文学翻译中的性别建构一以强势语为例 [Amplifier as an Index of Gender Construction in Literary Translation]. Foreign Languages in China. 12(6):82-89.

Mulac, Anthony and Lundell, Torborg (1994): Effects of Gender-linked Language Differences in Adults' Written Discourse: Multivariate Tests of Language Effects. Language and Communication. 14(3):299-309.

Mulac, Anthony, Wiemann, John, Widenmann, Sally, et al. (1988): Male/Female Language Differences and Effects in Same-sex and Mixed-sex Dyads: the Gender-linked Language Effect. Communication Monographs. 55(4):315-335.

Mulac, Anthony, Seibold, David and Farris, Jennifer (2000): Female and Male Managers' and Professionals' Criticism Giving: Differences in Language Use and Effects. Journal of Language and Social Psychology. 19(4):389-415.

Munday, Jeremy (2007): Translation and Ideology: A Textual Approach. The Translator. 13(2):195-217.

Newmark, Peter (1988/2001): A Textbook of Translation. Shanghai: Shanghai Foreign Language Education Press.

Niranjana, Tejaswini (1992): Sitting Translation: History, Post-Structuralism, and the Colonial Context. Berkeley/Los Angeles: University of California Press.

Olohan, Maeve (2004): Introducing Corpora in Translation Studies. London/New York: Routledge.

Palmer, Frank (1989): Mood and Modality. Cambridge: Cambridge University Press.

PuUrtinen, Tiina (1998): Translating linguistic markers of ideology. In: Andrew Chesterman, Natividad Gallardo San Salvador, and Yves Gambier, eds. Translation in Context. Selected papers from the EST Congress, Granada 1998. Amsterdam/Philadelphia: John Benjamins, 177-186.

Robinson, Douglas (1997): Translation and Empire. Manchester: St. Jerome.

Santaemilia, José (2005): Gender, Sex, and Translation: The Manipulation of Identities. Manchester: St. Jerome. 
Scott, Mike and Tribble, Christopher (2006): Textual Patterns: Key Words and Corpus Analysis in Language Education. Amsterdam/Philadelphia: John Benjamins.

Simpson, Paul (1993): Language, Ideology and Point of View. London/New York: Routledge.

Snell-Hornby, Mary (1988): Translation Studies: An Integrated Approach. Amsterdam/ Philadelphia: John Benjamins Publishing.

StubBs, Michael (1996): Text and Corpus Analysis. Oxford: Blackwell.

Toury, Gideon (1995): Descriptive Translation Studies and Beyond. Amsterdam/Philadelphia: John Benjamins.

VAn DijK, Teun (1998): Ideology: A Multidisciplinary Approach. London: Sage.

VAN DijK, Teun (2008): Discourse and Context. Cambridge: Cambridge University Press.

Venuti, Lawrence (1998): The Scandals of Translation: Towards an Ethics of Difference. London/ New York: Routledge.

Von Flotow, Luise (1997): Translation and Gender. Ottawa: University of Ottawa Press.

WANG, Xiaoli (2015): 民族意识形态与少数民族题材小说翻译——以《额尔古纳河右岸》英译为例 [Ethnic Ideology and Translation of Ethnic-themed Novels: A Case Study of the English Version of the Last Quarter of the Moon]. Foreign Languages in China. 12(6):90-98.

WANG, Xiaoyuan (2010): 翻译话语与意识形态一中国1885-1911文学翻译研究 [Translation Discourse and Ideology: Literary Translation in China, 1895-1911]. Shanghai: Shanghai Foreign Language Education Press.

Wodak, Ruth (1998): Language, Power and Ideology. Amsterdam/Philadelphia: John Benjamins.

Wu, Guangjun and Zhang, Huanyao (2015): Translating Political Ideology - A Case Study of the Chinese Translations of the English News Headlines concerning South China Sea Disputes on the Website of <www.ftchinese.com>. Babel. 61(3):394-410.

XIN, Bin (2005): 批评语言学: 理论与应用 [Critical Linguistics: Theory and Application]. Shanghai: Shanghai Foreign Language Education Press.

YANG, Liu (2010): 翻译诗学与意识形态 [Poetics of Translation and Ideology]. Beijing: Science Press.

ZAND, Fateme (2015): Translation of Hybrid Texts: Translator's Strategies and Ideologies in Translation of Funny in Farsi by Dumas. Asia Pacific Translation and Intercultural Studies. 2(3):208-223.

ZHU, Shenghao (1991): 《莎士比亚戏剧全集》译者自序 [The translator's preface]. In: Xianqiang MENG, ed. 中国莎士比亚评论 [Literary Criticism of Shakespeare in China]. Changchun: Jilin Education Press, 262-265.

ZHU, Xiaoming (2011): 批评话语分析视角下的《政府工作报告》英译研究(一)一基于语料库的 第一人称代词复数考察 [A Study of the English Translation of the Chinese Government Work Report from the Perspective of Critical Discourse Analysis (1) - A Corpus-based Study of the Use of the First Person Plural Pronoun]. Foreign Language Research. 25(2):7378 . 